\title{
A female-specific attractant for the codling moth, Cydia pomonella, from apple fruit volatiles
}

\section{Journal Article}

\section{Author(s):}

Hern, Alan; Dorn, Silvia

Publication date:

2004-02

\section{Permanent link:}

https://doi.org/10.3929/ethz-b-000051812

\section{Rights / license:}

In Copyright - Non-Commercial Use Permitted

\section{Originally published in:}

Naturwissenschaften 91(2), https://doi.org/10.1007/s00114-003-0484-6 


\section{Alan Hern · Silvia Dorn \\ A female-specific attractant for the codling moth, Cydia pomonella, from apple fruit volatiles}

Received: 3 April 2002 / Accepted: 20 October 2003 / Published online: 14 November 2003

(C) Springer-Verlag 2003

\begin{abstract}
Host plant-derived esters were investigated as potential female-specific attractants for the codling moth (CM), Cydia pomonella (L.), a key pest of apples worldwide. The behavioural effects of single and combined volatile compounds and of a natural odour blend were examined using olfactometry and wind-tunnel bioassays. The apple-derived volatile butyl hexanoate attracted mated females while it was behaviourally ineffective for males over a dosage range of more than three orders of magnitude in olfactometer assays. Female CM preferred this kairomone to the headspace volatiles from ripe apples. Both no-choice and choice trials in the wind-tunnel suggested that female moths might be effectively trapped by means of this compound. In contrast, headspace volatiles collected from ripe apple fruits as well as a blend containing the six dominant esters from ripe apples were behaviourally ineffective. A female-specific repellency was found for the component hexyl acetate in the olfactometer, but this ester had no significant effect in the wind-tunnel. Butyl hexanoate with its sex-specific attraction should be further evaluated for monitoring and controlling CM females in orchards.
\end{abstract}

\section{Introduction}

Male sex pheromones are used to monitor and control the codling moth (CM), Cydia pomonella (L.). However, control is only effective at low population levels and where immigration of gravid females is precluded (Cardé and Minks 1995). Field populations from various locations were found to contain females with the capacity for

\footnotetext{
A. Hern $\cdot$ S. Dorn $(\square)$

Institute of Plant Sciences, Applied Entomology,

Swiss Federal Institute of Technology (ETH),

8092 Zurich, Switzerland

e-mail: silvia.dorn@ipw.agrl.ethz.ch

Fax: +41-1-6321171
}

Present address:

A. Hern, Scottish Environmental Protection Agency,

Whitefriars Crescent, Perth, PH2 OPA, UK long flights, and this capacity is maintained even after mating (Dorn et al. 1999). Thus immigration of such gravid females may threaten orchards which are being protected by mating disruption technique. A semiochemical capable of attracting CM females would be desirable for monitoring and control, to complement the wellestablished techniques based on pheromones.

The pear-derived volatile ethyl $(2 E, 4 Z)-2,4$ decadienoate attracted both sexes (Light et al. 2001), while apple volatiles stimulated non-directed flight in females (Wearing et al. 1973). Evidence for a female-specific effect of an apple constituent was presented for $E, E-\alpha$ farnesene. This terpene was attractive at low, but repellent at high doses (Hern and Dorn 1999). It is of low environmental stability and thus of limited value for monitoring and control (Light et al. 2001). This led us to focus our search for female attractants on esters which are major constituents of ripe apples (Fein et al. 1982).

\section{Materials and methods}

Insects

CM were reared on artificial diet for 150-200 generations and tested 3-4 days after emergence. On emergence, males and females were placed together in a plastic cylinder with access to honey solution. Females were assumed to be mated as the moths were kept under conditions similar to those reported by Abivardi et al. (1998) who found an average of three spermatophores per female. For tests with virgin females, the pupae were sexed and the sexes were kept separately.

Methods

Bioassays were carried out using Y-tube olfactometry and windtunnel trials with both choice and no-choice tests.

Y-tube olfactometry

The moths were offered a dual choice in an all-glass Y-tube olfactometer (Hern and Dorn 1999). Silicon/teflon septa (11 mm in diameter) with $50 \mu \mathrm{l}$ of test odour were placed in tubular chambers of $35 \mathrm{~cm}$ length and $6 \mathrm{~cm}$ diameter. These chambers had a glass frit 
built in $11.5 \mathrm{~cm}$ from the air entrance to separate the source of the odour from the moth. The chambers were connected with PTFE tubing to the two $20-\mathrm{cm}$-long branches of the olfactometer which converged into a $20-\mathrm{cm}$-long common arm. These glass tubes had a diameter of $2.5 \mathrm{~cm}$. All joints were ground glass. Moistened, activated-charcoal-filtered air entered each arm at a flow rate of $750 \mathrm{ml} / \mathrm{min}$. Moths were placed individually at the entrance of the common arm. The position of the moth was recorded after 15 min. Behaviour was classified as no-choice if the moth remained in the common arm, and as choosing the test odour or the control (hexane), if it had entered one of the tubular chambers (Hern and Dorn 2002). Tests were conducted in the scotophase. A $60 \mathrm{~W}$ red light bulb allowed for behaviour observation.

Volatiles tested comprised (1) a blend of the six major apple esters, (2) the two largest components of the blend, and (3) headspace volatiles from ripe apple fruits.

1. A blend of the six major apple esters (Averill et al. 1988) was prepared using the following esters (purity $>98 \%$ ) in a ratio of 36:7:12:5:29:11 by weight, respectively: hexyl acetate, butyl-2methyl butanoate, propyl hexanoate, hexyl propanoate, butyl hexanoate and hexyl butanoate. This blend was diluted in hexane and loaded onto septa in doses of $1250 \mu \mathrm{g}$ to $1.25 \mu \mathrm{g}$ and $0.00125 \mu \mathrm{g}$ per septum, i.e. a six order of magnitude range.

2. The two largest components in the blend were tested separately at doses equivalent to those in the blend. The dosage range of butyl hexanoate was expanded for mated females to better characterise their dose-response.

3. Headspace volatiles from two ripe apples (var. Bohnäpfel, about $60 \mathrm{~g}$ each) were collected using a laboratory entrainment system for $12 \mathrm{~h}$ (Hern and Dorn 2001). For the bioassay, $50 \mu \mathrm{l}$ of this natural blend was tested against $50 \mu \mathrm{l}$ of a $5 \mathrm{ng} / \mu \mathrm{l}$ solution of butyl hexanoate, a quantity which corresponds to the amount of this constituent identified in the volatiles collected.

The volatiles were trapped using $0.3 \mathrm{~g}$ Tenax-TA (mesh size 60-80) over a $24 \mathrm{~h}$ period. The flow rate through the Tenax trap was $100 \mathrm{ml} / \mathrm{min}$, and the Tenax traps were replaced after $12 \mathrm{~h}$. Prior to sampling, the traps were thermally conditioned at $300^{\circ} \mathrm{C}$ for $4 \mathrm{~h}$ with a flow of helium through the trap (flow rate approximately $60 \mathrm{ml} / \mathrm{min}$ at ambient temperature $\sim 25^{\circ} \mathrm{C}$ ). Volatiles were eluted from the Tenax traps with $1 \mathrm{ml}$ of hexane (purity $99.5 \%$ ) and stored at $-20^{\circ} \mathrm{C}$ in glass vials with a PTFE silicon septum. Volatiles were pooled from each collection, and a subsample was taken to which methyl decanoate was added as an internal standard $(17 \mathrm{ng} / \mu \mathrm{l})$ for chemical analysis (Hern and Dorn 2001). Compounds were identified by a comparison of the sample spectra with a commercial (NIST 98) or user-created library, and the RT of the compound was matched with a standard. Where a compound is marked with a "+" (Table 1) the identification is based only on a comparison of the spectra with the NIST library. Quantification for all components except butyl hexanoate is relative to the internal standard peak area. For butyl hexanoate the quantification is based on the amount of ion 117 relative to the instruments calibration for this compound.

\section{Wind-tunnel trials}

The wind-tunnel was constructed from plexiglass $(0.35 \times 0.35 \times 1.5 \mathrm{~m}$ experimental area). Horizontally positioned acetate transparencies painted with insect glue were used as traps and placed adjacent to the odour sources. Vials with the test chemical were positioned at the upwind end of the trap. The no-choice bioassay used a single trap $(21 \mathrm{~cm}$ wide $\times 30 \mathrm{~cm}$ long) and the choice test two traps $(10 \mathrm{~cm}$ wide $\mathrm{x} 15 \mathrm{~cm}$ long), with a gap of $15 \mathrm{~cm}$ between them. These traps were placed on the floor of the wind-tunnel $4 \mathrm{~cm}$ from the upwind end. Charcoal-filtered air was pushed through the wind-tunnel at a rate of $31 \mathrm{~cm} / \mathrm{s}$. The moths were released in groups of 15 mated females at the downwind end, $3 \mathrm{~h}$ before the beginning of the scotophase $(6: 18 \mathrm{D}: \mathrm{L})$, and the trial lasted $17 \pm 1 \mathrm{~h}$. The order in which the treatments were tested was randomised. Each female was tested only once.
Table 1 Composition and quantification of constituents of ripe apple volatiles (var. Bohnäpfel) determined by GC-MS analysis, used in the dual choice olfactometer assay versus butyl hexanoate

\begin{tabular}{lr}
\hline Compound & $\begin{array}{c}\text { Constituent in olfactometer test } \\
(\mathrm{ng})\end{array}$ \\
\hline Butyl acetate & 280 \\
1-Hexanol & 55 \\
2-methyl butyl acetate & 250 \\
Butyl propanoate & 45 \\
Isopentyl acetate (+) & 20 \\
Butanoic acid, 2-methyl-, & 25 \\
propyl ester (+) & \\
Butyl butanoate & 80 \\
Hexyl acetate & 210 \\
Butyl 2-methylbutanoate & 95 \\
Propyl hexanoate & 40 \\
Hexyl propanoate & 65 \\
Butyl hexanoate & 250 \\
Hexyl butanoate & 90 \\
Hexyl 2-methylbutyrate & 210 \\
Isopentyl hexanoate & 10 \\
Butyl heptanoate & 25 \\
Propyl octanoate (+) & 15 \\
Hexyl hexanoate & 140 \\
Butyl caprylate & 70 \\
$E, E$-alpha farnesene & 380 \\
\hline
\end{tabular}

For the no-choice tests, the odour sources for each test consisted of five $0.35 \mathrm{ml}$ glass inserts placed into five wide-necked $2 \mathrm{ml}$ glass vials. For the lowest dose, one insert was filled with $100 \mu \mathrm{l}$ of chemical; for the second dose, three inserts were filled with $85 \mu \mathrm{l}$ each; and for the highest dose, five inserts were filled with $100 \mu \mathrm{l}$ each. Release rates over the trial period (mean $\pm \mathrm{SE}$ ), determined gravimetrically for the three dosages of butyl hexanoate, were $0.38 \pm 0.04 \mathrm{mg}, 1 \pm 0.12 \mathrm{mg}$ and $4.9 \pm 3.3 \mathrm{mg}$, and for hexyl acetate $2.6 \pm 0.09 \mathrm{mg}, 7.2 \pm 0.12 \mathrm{mg}$ and $13.6 \pm 1.7 \mathrm{mg}$. The control for all tests was empty glass vials with inserts.

For the choice tests, the odour source for each test consisted of five $0.35 \mathrm{ml}$ vials arranged in a line upwind of the traps, filled with chemical as in the no-choice trial, or left empty (control). Release rates over the trial period were determined gravimetrically for the three dosages as $0.37 \pm 0.033 \mathrm{mg}, 2.0 \pm 0.38 \mathrm{mg}$ and $2.7 \pm 0.55 \mathrm{mg}$. Data from these trials were analysed with generalised linear models using a Poisson distribution and a log-link Genstat. The significance of a factor was assessed by an analysis of deviance test on the model with and without the factor.

\section{Results}

Butyl hexanoate attracted mated CM females over a dosage range of three orders of magnitude in the olfactometer (doses $0.00125,0.36$ and $1.25 \mu \mathrm{g}$ ) (for results of statistical tests see Table 2). Outside this range the chemical was behaviourally ineffective (doses 0.00036, 362.5 and $1250 \mu \mathrm{g})$. The dosage of $0.36 \mu \mathrm{g}$ which attracted mated females was behaviourally ineffective for virgin females, as was the lower dose of $0.00036 \mu \mathrm{g}$, and repellence was noted for the highest dose of $362.5 \mu \mathrm{g}$.

Males did not respond to this chemical over the complete dosage range tested (doses 0.00036, 0.36 and $362.5 \mu \mathrm{g})$.

The "six-ester blend" was neither attractant nor repellent to males (doses $0.00125,1.25$ and $1250 \mu \mathrm{g}$ ) and females (doses 0.00125, 1.25 and $1250 \mu \mathrm{g}$ ) (Table 2). 
Table 2 Dual choice olfactometer assay. Preference of CM for test odour versus control (hexane unless indicated otherwise). $\mathrm{n}=50$ for each test

\begin{tabular}{|c|c|c|c|c|c|c|c|}
\hline \multirow[t]{2}{*}{ Test odour } & \multirow{2}{*}{$\begin{array}{l}\text { Concen- } \\
\text { tration } \\
(\mu \mathrm{g})\end{array}$} & \multirow[t]{2}{*}{ Moths tested } & \multicolumn{2}{|c|}{$\%$ choice for } & \multirow{2}{*}{$\begin{array}{l}\% \text { no } \\
\text { choice }\end{array}$} & \multirow{2}{*}{$\begin{array}{l}G \\
\text { statistic }\end{array}$} & \multirow[t]{2}{*}{$P$} \\
\hline & & & Test & Control & & & \\
\hline Butyl hexanoate ${ }^{a}$ & 0.00036 & Mated Female & 72.2 & 27.8 & 64 & 3.6 & 0.058 \\
\hline Butyl hexanoate & 0.00125 & Mated Female & 83.3 & 16.7 & 52 & 11.4 & $<0.001$ \\
\hline Butyl hexanoate & 0.36 & Mated Female & 75.0 & 25.0 & 60 & 5.1 & 0.024 \\
\hline Butyl hexanoate & 1.25 & Mated Female & 78.3 & 21.7 & 54 & 7.3 & 0.007 \\
\hline Butyl hexanoate & 362.5 & Mated Female & 58.3 & 41.7 & 52 & 0.7 & 0.42 \\
\hline Butyl hexanoate & 1250.0 & Mated Female & 63.0 & 37.0 & 46 & 1.8 & 0.18 \\
\hline Butyl hexanoate & 0.00036 & Virgin Female & 61.3 & 38.7 & 38 & 1.6 & 0.21 \\
\hline Butyl hexanoate & 0.36 & Virgin Female & 56.8 & 43.2 & 26 & 0.7 & 0.41 \\
\hline Butyl hexanoate & 362.5 & Virgin Female & 29.0 & 71.0 & 38 & 5.5 & 0.019 \\
\hline Butyl hexanoate & 0.00036 & Mated Male & 50.0 & 50.0 & 60 & 0.0 & 1.0 \\
\hline Butyl hexanoate & 0.36 & Mated Male & 40.0 & 60.0 & 50 & 1.0 & 0.32 \\
\hline Butyl hexanoate & 362.5 & Mated Male & 53.6 & 46.4 & 44 & 0.1 & 0.71 \\
\hline Six ester blend & 0.00125 & Mated Female & 69.2 & 30.8 & 74 & 1.9 & 0.17 \\
\hline Six ester blend & 1.25 & Mated Female & 52.9 & 47.1 & 66 & 0.1 & 0.81 \\
\hline Six ester blend & 1250.0 & Mated Female & 65.2 & 34.8 & 54 & 2.1 & 0.15 \\
\hline Six ester blend & 0.00125 & Mated Male & 42.9 & 57.1 & 72 & 0.3 & 0.60 \\
\hline Six ester blend & 1.25 & Mated Male & 41.7 & 58.3 & 76 & 0.3 & 0.57 \\
\hline Six ester blend & 1250.0 & Mated Male & 45.5 & 54.5 & 78 & 0.1 & 0.77 \\
\hline Hexyl acetate ${ }^{b}$ & 0.00045 & Mated Female & 33.3 & 66.7 & 70 & 1.6 & 0.20 \\
\hline Hexyl acetate & 0.45 & Mated Female & 20.0 & 80.0 & 60 & 7.5 & 0.006 \\
\hline Hexyl acetate & 450.0 & Mated Female & 30.8 & 69.0 & 48 & 3.9 & 0.049 \\
\hline Hexyl acetate & 0.00045 & Virgin Female & 65.4 & 34.6 & 48 & 2.5 & 0.12 \\
\hline Hexyl acetate & 0.45 & Virgin Female & 25.0 & 75.0 & 52 & 6.2 & 0.013 \\
\hline Hexyl acetate & 450.0 & Virgin Female & 30.0 & 70.0 & 40 & 4.9 & 0.027 \\
\hline Hexyl acetate & 0.00045 & Mated Male & 48.1 & 51.9 & 46 & 0.04 & 0.85 \\
\hline Hexyl acetate & 0.45 & Mated Male & 55.6 & 44.4 & 64 & 0.2 & 0.64 \\
\hline Hexyl acetate & 450.0 & Mated Male & 70.6 & 29.4 & 66 & 2.9 & 0.089 \\
\hline Ripe apple volatiles $^{\mathrm{c}}$ & & Mated Female & 35.7 & 64.3 & 72 & 1.1 & 0.29 \\
\hline $\begin{array}{l}\text { Butyl hexanoate } \\
\text { versus ripe apple } \\
\text { volatiles (control) }\end{array}$ & & Mated Female & 81.8 & 18.2 & 78 & 4.6 & 0.032 \\
\hline
\end{tabular}

${ }^{a}$ Purity $>98 \%$ Aldrich Flavour and Fragrance

${ }^{b}$ Purity $>99.5 \%$ Supelco

${ }^{\mathrm{c}}$ Identification of constituents and analysis of their quantitative composition by GC-MS; see text and Table 1
Hexyl acetate was repellent to mated females at doses of 0.45 and $450 \mu \mathrm{g}$ and behaviourally ineffective at a dose of $0.00045 \mu \mathrm{g}$. An identical pattern was obtained for virgin females, as this ester was repellent at doses of 0.45 and $450 \mu \mathrm{g}$ and behaviourally ineffective at a dose of $0.00045 \mu \mathrm{g}$. In contrast, it was behaviourally ineffective for males (doses 0.00045, 1.25 and $1250 \mu \mathrm{g}$ ) (Table 2).

Butyl hexanoate was further tested against ripe apple volatiles in the olfactometer (Table 2). This single component was significantly preferred over the headspace volatiles from ripe apples by mated $\mathrm{CM}$ females. The ripe apple volatiles were behaviourally ineffective when tested against a solvent control.

In the wind-tunnel no-choice tests, significant differences were apparent in the moths' behaviour dependent on the treatment $(F=6.5 ; d f=6.28 ; P>0.001)$ (see Fig. 1a). Butyl hexanoate at the lower two dosages tested trapped higher numbers of CM females than the control [Wald's test statistic $=2.4, P=0.022$ and Wald's test statistic $=3.5$, $P<0.001$ for 0.4 and $1 \mathrm{mg}$ doses, respectively (Crawley 1993)]. The effect of the highest butyl hexanoate dose tested did not differ from the control (Wald's test statistic $=0.98, P=0.33)$. Hexyl acetate was behaviourally ineffective in the wind-tunnel no-choice tests at all doses tested (Wald's test statistic $=-1.3, P=0.21$; Wald's test statistic $=-0.78, P=0.44$ and Wald's test statistic $=0.15$, $P=0.88$ for the $2.6,7.2$ and $13.6 \mathrm{mg}$ doses, respectively).

In the wind-tunnel choice tests, there was no significant effect of the dose tested $(F=1.8 ; d f=2,15 ; P=0.20)$, nor was the interaction significant between the number of moths trapped in each treatment and the dose $(F=0.2 ; d f=2,14$; $P=0.67$ ) (Fig. 1b). However, approximately twice as many $\mathrm{CM}$ females were caught on the butyl hexanoate traps than on the control traps $(F=9.7 ; d f=1,16 ; P=0.007)$.

\section{Discussion}

Butyl hexanoate can be considered an attractant for mated female CM. It is a major component of ripe apple fruits, accounting for more than $10 \%$ of the total headspace volatiles emitted (Fein et al. 1982; Table 1).

A blend comprising the six major esters of ripe apple odour including butyl hexanoate was behaviourally ineffective for CM females. This non-preference for the apple volatiles by the moths may be an indication that this mixture also contains repellents. For example, hexyl acetate was repellent under the same olfactory conditions. $\alpha$-Farnesene, a further major constituent of ripe apple volatiles, is attractive at the dosages used in this study, as 

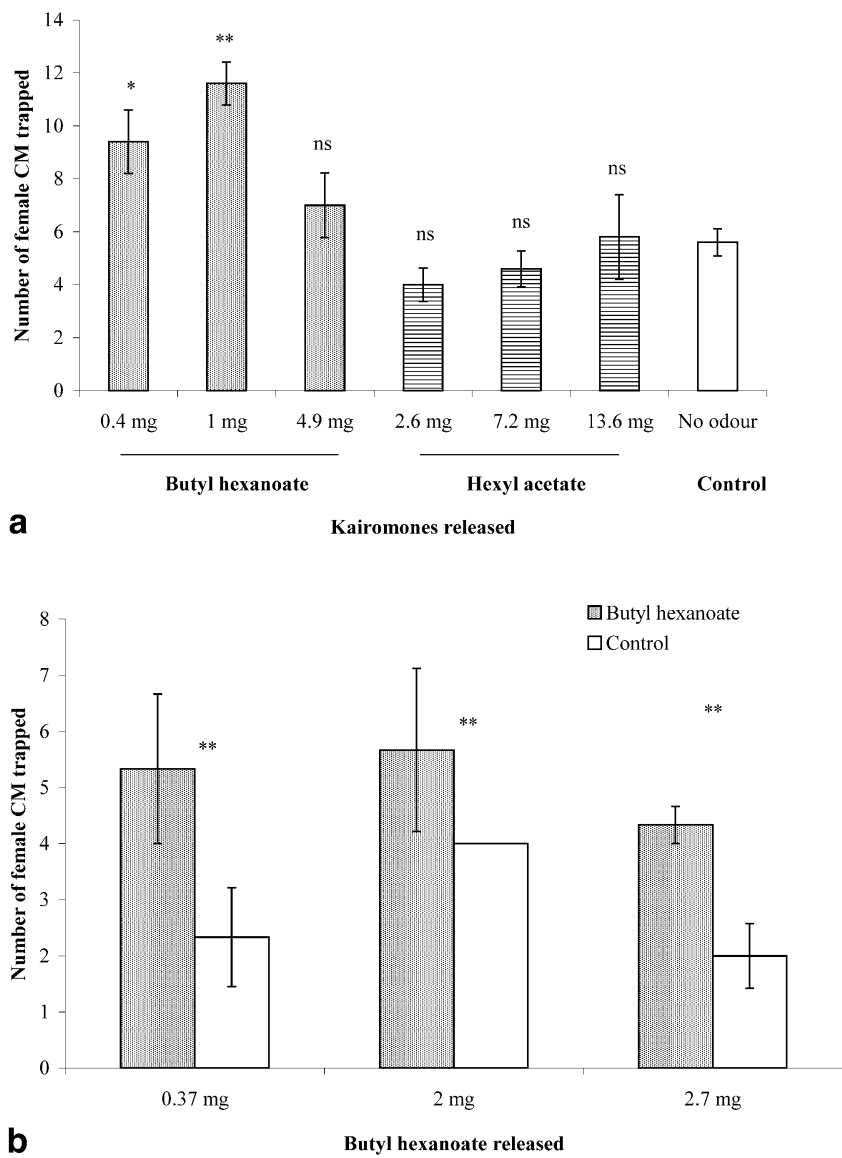

Fig. 1 a No-choice assay in the wind-tunnel. Response of mated codling moth females to butyl hexanoate and hexyl acetate; $n=5$ for each treatment, 15 moths per trial, ns denotes $P>0.05$, * indicates $P<0.05$ and $* * \mathrm{P}<0.01$ for comparisons between control and each treatment based on parameter estimates from a generalised linear model for treatment effect. b Dual-choice assay in the wind-tunnel. Response of mated codling moth females to butyl hexanoate versus control; $n=3$ for each dose of butyl hexanoate tested, 15 moths per trial, ** indicates $P<0.01$ for difference between treated and control traps. SE for medium dose trap control is 0

can be deduced from previous data obtained from testing the single component (Hern and Dorn 1999). Neither the effect of this or other chemicals in a blend is easily predictable, however. The complexity of the interactions between components precludes a simple additive analysis.

As ripe apple volatiles failed to attract CM females, it is not obvious that a single constituent should be an attractant. Female attraction was recently found for apple branches with leaves and immature fruitlets (Yan et al. 1999), for dichloromethane extract of cut immature fruitlets (Hughes et al. 2003) as well as for ripening fruit infested with CM larvae (Hern and Dorn 2002). CM females responded to 17 constituents of apple fruit volatiles, including butyl hexanoate, with electroantennogram activity (Bengtsson et al. 2001; Witzgall et al. 1999). As for the esters, a further olfactometer bioassay indicated an attraction of CM females to hexyl hexanoate (Hern and Dorn 2001). Additional constituents of apple fruits may elicit behavioural activity (Hern and Dorn 2003). Butyl hexanoate, as a key representative of bioactive carboxylic acid esters, should be evaluated further as a candidate for $\mathrm{CM}$ female-specific monitoring and control in orchards.

Acknowledgements We thank Dr. R. Kaiser (Givaudan-Roure, Duebendorf, Switzerland), who provided many of the standards for the GC-MS analysis, and Drs. K. Tschudi-Rein and J. Samietz for useful comments. A patent application by S. Dorn and A. Hern has been filed for this discovery.

\section{References}

Abivardi C, Weber DC, Dorn S (1998) Effects of azinphos-methyl and pyrifenox on reproductive performance of Cydia pomonella L. (Lepidoptera: Tortricidae) at recommended rates and lower concentrations. Ann Appl Biol 132:19-33

Averill AL, Reissig WH, Roelofs WL (1988) Specificity of olfactory responses in the tephritid fruit fly, Rhagoletis pomonella. Entomol Exp Appl 47:211-222

Bengtsson M, Bäckman AC, Liblikas I, Ramirez MI, Borg-Karlson AK, Ansebo L, Anderson P, Löfqvist J, Witzgall P (2001) Plant odor analysis of apple: antennal responses of codling moth females to apple volatiles during phenological development. J Agric Food Chem 49:3736-3741

Cardé RT, Minks AK (1995) Control of moth pests by mating disruptions: successes and constraints. Annu Rev Entomol 40:559-585

Crawley M (1993) GLIM for ecologists. Blackwell Science, Oxford

Dorn S, Schumacher P, Abivardi C, Meyhöfer R (1999) Global and regional pest insects and their antagonists in orchards: spatial dynamics. Agric Ecosyst Environ 73:111-118

Fein BL, Reissig WH, Roelofs WL (1982) Identification of apple volatiles attractive to the apple maggot, Rhagoletis pomonella. J Chem Ecol 8:1473-1487

Hern A, Dorn S (1999) Sexual dimorphism in Cydia pomonella in response to $\alpha$-farnesene. Entomol Exp Appl 92:63-72

Hern A, Dorn S (2001) Statistical modelling of insect behavioural responses in relation to the chemical composition of test extracts. Physiol Entomol 26:381-390

Hern A, Dorn S (2002) Induction of volatile emissions from ripening apple fruits infested with Cydia pomonella and the attraction of adult females. Entomol Exp Appl 102:145-151

Hern A, Dorn S (2003) Monitoring seasonal variation in apple fruit volatile emissions in situ using solid-phase microextraction. Phytochem Anal 14:232-240

Hughes WO, Gailey D, Knapp JJ (2003) Host location by adult and larval codling moth and the potential for its disruption by the application of kairomones. Entomol Exp Appl 106:147-153

Light DM, Knight AL, Henrick CA, Rajapaska D, Lingren W, Dickens JC, Reynolds KM, Buttery RG, Merrill G, Roitman J, Campbell BC (2001) A pear-derived kairomone with pheromonal potency that attracts male and female codling moth, Cydia pomonella (L.). Naturwissenschaften 88:333-338

Wearing CH, Connor PJ, Ambler KD (1973) Olfactory stimulation of oviposition and flight activity of the codling moth Laspeyresia pomonella, using apples in an automated olfactometer. $\mathrm{N} \mathrm{Z}$ J Sci 16:697-710

Witzgall P, Bengtsson M, El-Sayed A, Bäckman AC, Rauscher S, Borg-Karlson AK, Unelius CR, Löfqvist J (1999) Chemical communication in codling moth: towards environmentally safe control methods. IOBC WPRS Bull 22:57-65

Yan F, Bengtsson M, Witzgall P (1999) Behavioural response of female codling moths, Cydia pomonella, to apple volatiles. J Chem Ecol 25:1343-1351 